\title{
The prescribing of prisms in clinical practice
}

\author{
Lyle S. Gray
}

Received: 15 February 2008 / Accepted: 19 February 2008 /Published online: 1 April 2008

(C) Springer-Verlag 2008

\begin{abstract}
The use of prisms in cases of decompensated heterophoria is an established treatment modality. The clinical literature lacks consensus upon the appropriate use of prisms, and fails to provide the necessary evidence base. While the experimental literature can guide the practitioner, the lack of double-blind, placebo-controlled clinical studies needs to be addressed.
\end{abstract}

\section{Keywords Prisms $\cdot$ Binocular $\cdot$ Vergence adaption}

The use of prisms in cases of binocular dysfunction is an important treatment modality for dealing with such patients [1]. The decision to prescribe a prism, and what value of prism to give, is subject to varying clinical opinions and practices [2]. The conservative view in clinical practice is that prisms should not be prescribed in the absence of symptoms of binocular dysfunction [1]. Furthermore, the prescribing of prisms is contraindicated in certain cases, due to the risk of exacerbating an existing condition through the process of vergence adaptation [3-6].

The control of the vergence response has been described previously using linear systems modelling [7], and can aid our understanding of the aetiology of binocular visual dysfunction, and the effect of clinical intervention. The normal vergence response operates in a closed-loop feedback system, where the total response is the sum of the outputs of two control elements with differing temporal

L. S. Gray $(\bowtie)$

Department of Vision Sciences, Glasgow Caledonian University, Cowcaddens Road,

Glasgow G4 0BA, UK

e-mail: 1sgr@gcal.ac.uk properties; a fast (phasic) control element and a slow (tonic) adaptive control element [7].

Previous reports have suggested that the strength of the adaptive vergence control element is often related to the presence of symptoms in patients with binocular dysfunction, and in severe cases the output of the adaptive vergence controller may be reduced to almost zero [8, 9]. In less severe cases, vergence adaptation may be present at a sub-normal level, but sufficient to produce an adaptive response to the introduction of a prism [8]. In such patients, strengthening the adaptive vergence control element is the treatment of first choice $[8,9]$. Other studies have shown that in elderly patients vergence adaptation is very limited, and that while this may often be the cause of binocular dysfunction in these patients, remedial action with prisms is clinically viable because adaptation is very unlikely [10]. Indeed, we observe in our own binocular vision clinic that treatments designed to improve the strength of the adaptive vergence controller are generally unsuccessful in elderly patients.

Typical clinical measures of binocular function, three of which are investigated by Otto et al. [11] in the current issue, are:

1. Heterophoria (or dissociated phoria).

This represents the fusion-free position of the eyes, and therefore the magnitude of the deviation which has to be overcome by the vergence system.

2. Fixation disparity.

First investigated by Ogle [12], this represents a small misalignment of the visual axes during binocular viewing, normally measured in seconds of arc. Many clinicians take the view that fixation disparity is indicative of stress within the binocular system [1]. Other authors regard fixation disparity to be a purposeful error, necessary for the vergence control system [5]. 


\section{Associated heterophoria}

Mallett $[13,14]$ is the author associated with describing the clinical characteristics of this measurement, which measures the amount of prism required to reduce any fixation disparity (in 2 above) present to zero. In Mallett's opinion, the presence of an associated phoria in a patient with symptoms of binocular vision dysfunction is indicative of stress within the binocular system, and requires treatment [15].

\section{Fusional vergence reserves.}

This is a clinical measure of the overall ability of the vergence system to control heterophoria. It is generally used in the calculation of Sheard's Criterion [16], which requires the vergence reserves to be at least twice the size of any heterophoria present. There is evidence that the vergence reserves are related to the strength of the adaptive component of the vergence system $[8,9]$.

Each of these measures assess one specific aspect of binocular function, and while some practitioners prefer to rely on a particular measure to assess binocular function, others may assess a combination of the measures above to decide the most appropriate clinical intervention for the patient [2].

There is a lack of consensus in the literature about which of these measures correlates most closely with symptoms of binocular dysfunction, and which provides the most accurate basis for prescribing a prism when this is appropriate. Previous work has shown that no single measure correlates well with patient symptoms in all types of binocular anomaly, suggesting that neither fixation disparity, nor associated phoria, provide a universal indicator of binocular dysfunction [17]. This work also found that measures of vergence reserves often showed a better correlation with symptoms [17].

The imperative question for the clinician remains; is there a reliable method to determine the magnitude of prism required to compensate the heterophoria in patients suitable for this method of treatment? Mallett [15] suggested that the associated heterophoria identified the uncompensated portion of the binocular anomaly, and therefore this value represented the prism required to give the patient binocular comfort and stability. Other studies have questioned this [5, 17], and indeed the presence of an associated phoria in patients without binocular visual problems casts doubt on the general applicability of this measure [18]. Sheard's criterion provides a rationale for prescribing prisms $[1,18]$; however, there is still a lack of randomised controlled clinical trials to prove the efficacy of any treatment of binocular vision [2], although a recent study has begun to address this [19]. The use of a measure such as the "comfortable prism", while clinically appealing, is highly subjective in nature, and would also require a clinical evidence base to prove efficacy. There is considerable work still to be done in the field of clinical management of binocular vision dysfunction in order to provide the required evidence base.

In all cases of binocular dysfunction, the choice to prescribe prisms lies with the clinician, who must judge what is most appropriate for each individual patient. A relatively straightforward procedure has been described to assess the probability of vergence adaptation occurring and rendering any prescribed prism ineffective [20]. Where prism treatment is being considered, obtain a prior measurement of the associated phoria, insert the prism to be prescribed into the trial frame and measure the associated phoria with the prism in situ. Allow the patient to wear the prism for 10 minutes; if the associated phoria returns to the value measured prior to insertion of the prism, then the patient's vergence adaptation mechanism has been strong enough to overcome the prism, and it will have little clinical benefit. Conversely, if no vergence adaptation is observed, the patient is likely to derive significant clinical benefit from this treatment.

Acknowledgements The author would like to acknowledge the useful comments of Drs Niall Strang and Dirk Seidel in the preparation of this editorial.

\section{References}

1. Evans BJW (2002) Pickwell's Binocular Vision Anomalies, 4th edn. Butterworth-Heinemann, Oxford

2. O' Leary CI, Evans BJW (2003) Criteria for prescribing optometric interventions: literature review and practitioner survey. Ophthal Physiol Opt 23:429-439

3. North RV, Henson DB (1981) Adaptation to prism induced heterophoria in subjects with abnormal binocular vision or asthenopia. Am J Optom Physiol Opt 58:746-752

4. North RV, Henson DB (1982) Effect of orthoptics upon the ability of patients to adapt to prism-induced heterophoria. Am J Optom Physiol Opt 59:983-986

5. Schor CM (1983) Fixation disparity and vergence adaptation. In: Schor CM, Ciuffreda KJ (eds) Vergence eye movements: basic and clinical aspects. Butterworths, Boston

6. Lie I, Opheim A (1985) Long term acceptance of prisms by heterophorics. J Am Opt Assoc 56:272-278

7. Schor CM, Kotulak JC (1986) Dynamic interactions between accommodation and convergence are velocity sensitive. Vision Res 26:927-942

8. North RV, Henson DB (1992) The effect of orthoptic treatment upon the vergence adaptation mechanism. Optom Vis Sci 69:294-299

9. Schor C, Horner D (1989) Adaptive disorders of accommodation and vergence in binocular dysfunction. Ophthal Physiol Opt 9:264-268

10. Winn B, Gilmartin B, Sculfor DL et al (1994) Vergence adaptation and senescence. Optom Vis Sci 71:797-800

11. Otto JMN, Kromeier M, Bach M, Kommerell G (2008) Do dissociated or associated phoria predict the comfortable prism? Graefes Arch Clin Exp Ophthalmol [in press]

12. Ogle KN (1964) Researches in Binocular Vision. Hafner, New York

13. Mallet RFJ (1964) The investigation of heterophoria at near and a new fixation disparity technique. Optician 148:547-551 
14. Mallet RFJ (1966) A fixation disparity test for distance use. Optician 152:1-8

15. Mallett RFJ (1974) Fixation disparity - its genesis and relation to asthenopia. Ophthal Opt 14:1159-1168

16. Sheard C (1930) Zones of ocular comfort. Am J Optom 7:9-25

17. Sheedy JE, Saladin JJ (1983) Validity of diagnostic criteria and case analysis in binocular vision disorders. In: Schor CM, Ciuffreda KJ (eds) Vergence eye movements: basic and clinical aspects. Butterworths, Boston
18. Grisham JD (1983) Treatment of binocular dysfunctions. In: Schor CM, Ciuffreda KJ (eds) Vergence eye movements: basic and clinical aspects. Butterworths, Boston

19. O' Leary CI, Evans BJW (2006) Double-masked randomised placebo-controlled trial of the effect of prismatic corrections on the rate of reading and the relationship with symptoms. Ophthal Physiol Opt 26:555-565

20. Rosenfield M (1997) Tonic vergence and vergence adaptation. Optom Vis Sci 74:303-328 